\title{
Low-Cost Pulmonary Ventilator for Patient Monitoring for Covid-19 Disease
}

\author{
Md Abdullah Al Rakib, Md. Moklesur Rahman, MousumeSamad, Sanjib Islam, \\ Md. Ashiqur Rahman, and Fysol Ibna Abbas
}

\begin{abstract}
Positive pressure ventilation has been an important component of respiratory disease management for the last 50 years. External instruments called ventilators are intended to help a patient accomplish a certain operation. It is to maintain or enhance a person's breathing capacity if he has a problem with his own breathing. It is a piece of equipment, software application, or product scheme that is used to increase, sustain, or boost the functional capacities of people with pulmonary difficulties. The developed system of a lab model ventilator is the subject of this article. The ventilator's robustness and functionalities, which are not only easily adaptable but also exact lower cost and cost-effective. The proposed design for a ventilation system was constructed with wooden parts weighing $6 \mathrm{~kg}$ and measuring $14 \times 7 \times 9$ inches in dimension. It works without essential to the human hand since it breathes by the compression of a traditional bag-valve mask. In addition, it has a low-battery warning system as well as an assist control. Thismethod implemented is novel, low - cost, less dependent on external power and easy to manage.
\end{abstract}

Key words - air pressure, AMBU bag, bag valve mask, Restoration mask, ventilator.

\section{INTRODUCTION}

Ventilators are important in human life. It gets its energy from a battery-powered electric motor that runs at 24 volts DC. The main goal of this article is to teach you about medical ventilation systems, microcontroller programming, how to build a ventilation system, how to control pressure with a setting key, how to control a gear motor, and how to control motor speed. Different functions are needed for breathing, such as pressure and the required amount of breaths per minute, which are regulated by a simple input board with buttons. In addition, it has a low-battery warning system as well as an assist control. This proposed ventilator concept costs $\$ 150$, but once commercial production is scaled up, cost savings will be realized, and it will be available for $\$ 100$ [1].

In terms of current ventilator technology, this piece of prototype is both cost and energy efficient. Based on the characteristics mentioned above, it can be considered a viable

Submitted on September 27, 2021.

Published on October 31, 2021.

Md Abdullah Al Rakib, Dept. of Electrical and Electronic Engineering, City University, Dhaka-1216, Bangladesh.

Faculty of Science, University of Dhaka, Dhaka-1000, Bangladesh

Md. Moklesur Rahman, Faculty of Science, University of Dhaka, Dhaka-1000, Bangladesh.

Mousume Samad, Dept. of Information and Communication Engineering, Bangladesh Army University of Engineering and Technology, Natore-6431, Bangladesh.

Sanjib Islam, Faculty of Science, University of Dhaka, Dhaka-1000, Bangladesh. alternative. To design the medical ventilation system, the project's criteria were first closely studied. This project's approach may be detached into two sections that are software and hardware applications. To determine future improvements, data was gathered from reference books and websites. The required components were obtained from the local market [2].

In the event that the lungs collapse, automated ventilation is desired for the diseases mentioned above. This prototype would assist a patient in inhaling and exhaling so that carbon dioxide and oxygen will be exchanged, and the patient will live with artificial respiration. The cost of ventilators, which are still in operation in most pre-village hospitals, is prohibitive. Poor nations seem to be reluctant to provide such facilities, and the reason for this is obvious: the high costs of accessing and using them. As a result, their upkeep is also an expensive company expense. Another issue in those developed countries is the attention of vital facilities in urban areas only [3].

Eight babies died of pneumonia due to a lack of ventilators in the hospital as a result of such a shortage in a Lahore region. This obviously demonstrates that there is a ventilator deficit in hospitals. As previously said, the high cost of commercially available ventilators is a significant cause of this shortage. As a result, such prototypes will alleviate costrelated issues in developing countries [4].

\section{PROTOTYPE DESIGN}

Although the ventilators used in today's emergency rooms are extremely practical and revolutionary, their acquisition costs are correspondingly high. Due to exorbitant costs, such innovatively sophisticated mechanical systems are prohibitively expensive for use in asset-poor countries. Furthermore, these ventilators are often brittle and powerless when used repeatedly, necessitating costly administration contracts from the manufacturer [6]. This has led to activities such as exchanging ventilators among emergency clinics and purchasing less reliable upgraded units in developing countries.

Dept. of Electrical \& Electronic Engineering, Independent University, Dhaka-1229, Bangladesh.

Md. Ashiqur Rahman, Faculty of Science, Comilla University, Comilla -3506, Bangladesh.

Graduate School of Science, Tokyo Metropolitan University, 1-1, Minami-osawa, Hachioji 192-0397, Japan.

Fysol Ibna Abbas, Dept. of Electrical and Electronic Engineering, City University, Dhaka-1216, Bangladesh.

Faculty of Science, University of Dhaka, Dhaka-1000, Bangladesh

Graduate School of Science, Tokyo Metropolitan University, 1-1, Minami-osawa, Hachioji 192-0397, Japan.

(e-mail: fysolibnaabbas ${ }^{\circledR}$ gmail.com). 
As almost the first model was incorporated with the core concept of collecting documents of needed amounts of energy and forces, the single arm idea was the comer technique for BVM compression. It was done in order to predict the machine's functioning requirements. The devices are put constructed using four wooden components that are joined together with nails and wooden glue. The foundering wooden piece is used to secure them. The factual is modest to cut and attach [5].

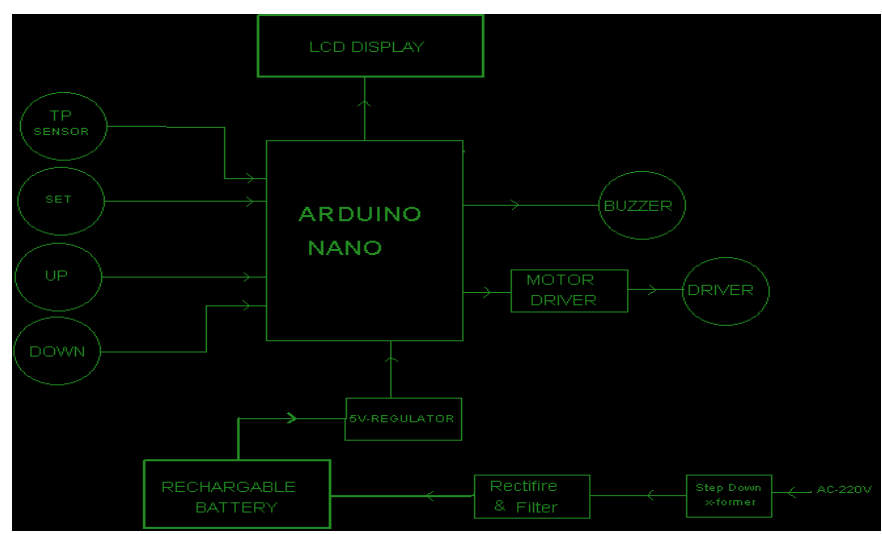

Fig. 1. Block diagram of this work.

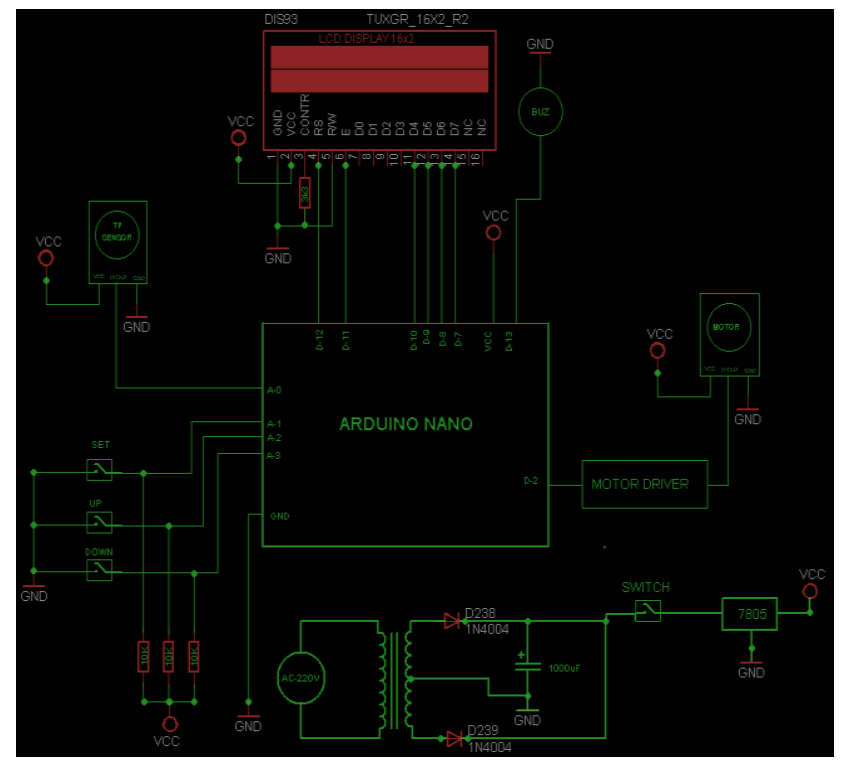

Fig. 2.Circuit diagram of this work.

On the vertical sheet, one hole was drilled, and on the opposite sheet, a larger hole was drilled. These two holes were drilled into it. The BVM's two ends were inserted into these two holes. There under BVM, wooden pieces were put to show assistance from the bottom. The top of the design was left exposed for element testing and inspection [7].

Even the first test was carried out in order to unlock the machine's performance criteria. The prototype's single arm system yielded useful information. The outgoing pressure difference from the BVM was measured using an analog airflow sensor. The motor's motion was altered in response to the pressure sensor's needed values. Based on these tests, it was determined that the highest amount of electricity necessary for the machine to work was 24 watts, as well as the highesttorque was 0.75 newton meter. The greatest amount of fluid supplied each stroke was around $700 \mathrm{~mL}$. As a result, for huge mainstream for clinical circumstances, this is sufficient [8].

As moveable elements were included into the enclosures, enhancements were made based on the fundamental correcting features and insights gained from the original solution of the device. The enclosure's proportions were enlarged to accommodate the iron arm's mobility in a more manageable manner. In addition, specific preparations were created for the microcontroller, battery, and motor. The upper half of the enclosure was constructed of clear acrylic, with holes drilled from the unit's side to house the LCD and buttons. Blocks erected for the purpose of support were also moved further beneath the Ambu. A potentiometer was also linked to the LCD, which could be used to raise the intensity of the display depending on the surroundings (shadow or sunlight) [9].

In the control layout, the ventilator was operated in three different modes. There were different modes: child, infant, and adult. Because various age groups had distinct breathing needs, the pressure and speed of each of those were variable. These specifications are listed in the table under [10].

\begin{tabular}{cc}
\multicolumn{2}{c}{ TABLE I: AGEAND BREATHING } \\
\hline Age Group & Breaths per Minute (BPM) \\
\hline 6 month & $30-40$ \\
10 year & $17-23$ \\
Adult & $12-18$ \\
\hline
\end{tabular}

By just pushing the appropriate mode button, the desired mode may be activated. If someone wishes to utilize the baby mode, they will need to modify the Ambo Bag as well. Because the backpacks for adults and newborns are varied [11].

To start the work, let's acquire a general overview of all of the elements we'll be using. It is critical to have complete knowledge of both hardware and software requirements. The following are the parts we're using Breadboard, Arduino Nano (ATmega328), 103 temperature sensor, LCD Display with header $(16 \times 2)$, adapter (AC to DC $12 \mathrm{~V}$ ), DC gear motor, button, beeper, and ventilation Set.

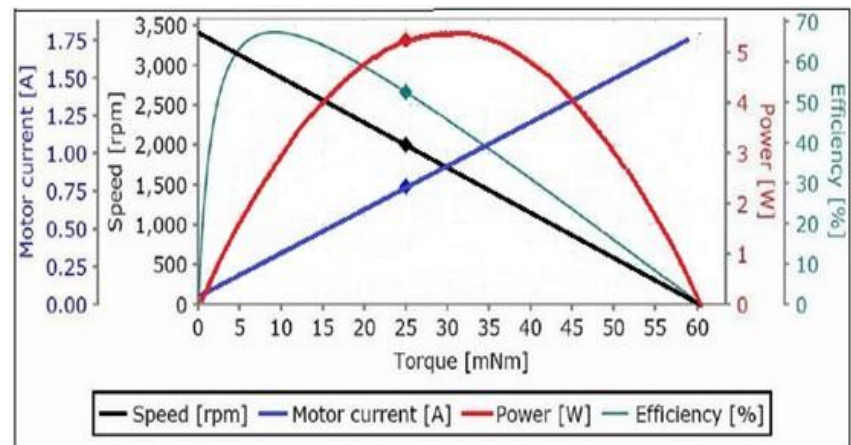

Fig.3. Gearing motor presentation curves.

It is a $16 \mathrm{MHz}$ microcontroller board with a serial hardware port, 6 ADC inputs, 14 digital I/O pins and a power rating of 5 volts, based on the ATmega 328 microcontroller [12]. The main benefit of Arduino is that programmes, without having any hardware programming to graze the program, can be put straight into the device. Five steps to schedule an Arduino are known. A precise integrated circuit temperature measurement device has been utilized with the LM35 sensor. The LCD screen has been utilized to provide a large range of applications and is an electronic display module [13]. 
From the above curve we can get this equation (1).

$$
Y=0096 x+0.0057
$$

As the name indicates, the self-expanding bag spontaneously inflates without a gas supply. It is constantly inflatable, ready for use and portable as this is not reliant on on a compressed foundation for rise. The self-expanding bag has four parts: Oxygen supply, air supply, valve assembly and patient supply [14].

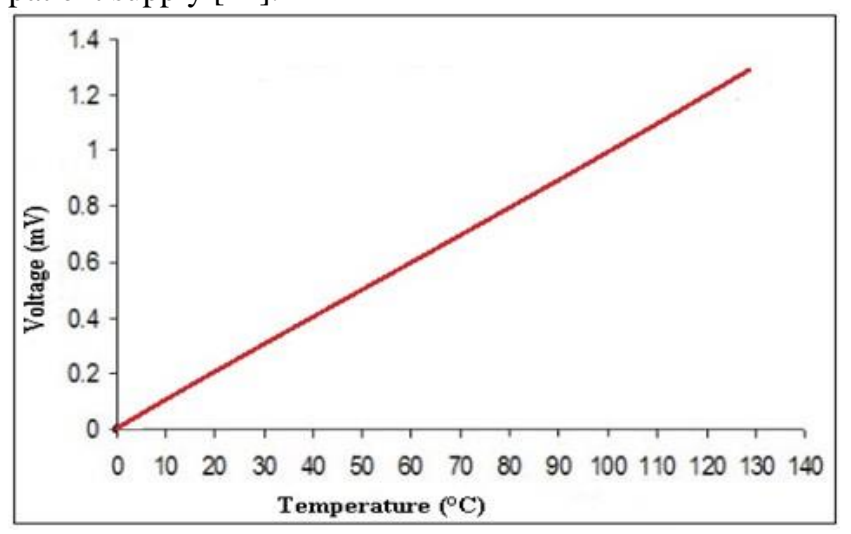

Fig.4. LM35 characteristic curve.

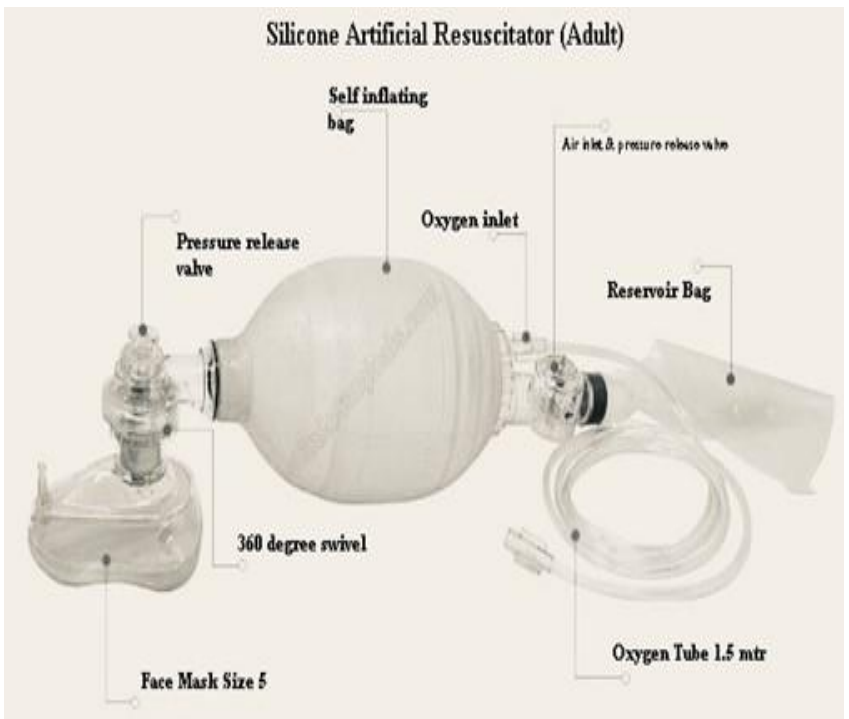

Fig. 5. AMBU bag.

When the bag is restored to compression, air is sucked into the bag via a one-way valve at either end of the bag. Small extension or protrusion to the oxygen intake situated adjacent to the air inlet can be connected to the oxygen tubes [15]. An oxygen line is not required for the bag to work in the selfinflating bag. It should only be attached if the child is raised with a combination of oxygen-enriched air instead of room air. Air passes via a mask or an endotracheal tube in the patient's departure from bag to baby. Self-inflated bags are placed between the bag and patient exit using a valve assembly [16].

In the case of newborns with backup for supplementary oxygen, the NRP recommended that room air recovery be started in the term if the baby doesn't improve, despite 90 seconds' efficient ventilation. As oxygen is regarded as a medication it must be carefully monitored in its usage in newborns. The usage of an oxygen reservoir can obtain high levels of oxygen with a self-expanding bag. A reservoir of oxygen is an instrument that is fitted via the air intake of the bag. It has a high concentration of oxygen in a chamber [17].

\section{A. Restoration Masks}

Restoration masks occur in numerous formulas, dimensions and tools. The choice of a special mask for a certain child depends on how well it is appropriate for the face of the child. Reanimation masks feature either coiled or uncoiled rims. Non-cushioned masks are not soft and hence stiff, abrupt, and have either a soft, flexible substance, like foam or an air-inflated ring. Cushioned masks are constructed of a soft, flexible material like foam. Masks can be rectangular or circular.

Round: A round mask can achieve a ventilation screen. It may not fit above the nose and mouth properly when the mask is too small. The impact on the eye might be applied if the cover is excessively wide. Anatomically: Some masks are designed to match the facial contours. Such covers are known as masks in anatomical form. They are put on the face to the most points of the masks on the nose. A seal with an architectural mask is easy to achieve [18]-[25].

\section{B. Security Features}

There are some security topographies. In order to avoid excessive pressure from unintentionally coming into the lungs, two safety measures are included in resuscitation bags. Every neonatal resuscitation bag should include at least one of these two qualities. The first is a pressure release valve, often called a pop-off valve or a security valve. These valves are configured to discharge $30-40 \mathrm{~cm}$ of water. Thus, if pressures over that limit are created, the valve opens and avoids the transmission of the extra pressure to the child. The emergency valve can be covered momentarily to permit water pressure of above $40 \mathrm{~cm} \mathrm{[26]-[28].}$

This can be essential to ventilate the rigid, unrated lungs of a newborn, particularly during the first few respirations. A pressure gauge should be connected to any self-inflated bag that allows the pop-off valve to be circumvented. The second security function is a pressure gauge or manometer that measures the high pressure of inspiration.

TABLE II: COST BALANCE

\begin{tabular}{cccc}
\hline & Name & Quantity & Price in TK \\
\hline Arduino Nano & 1 & 300 \\
Gear Motor & 1 & 2500 \\
2x16 LCD & 1 & 200 \\
24v step-down transformer & 1 & 1000 \\
Ventilation set & 1 & 2000 \\
Bridge diode & 1 & 100 \\
2200uf capacitor & 1 & 50 \\
7805 voltage regulator & 1 & 30 \\
AC Cord & 1 & 50 \\
470uf capacitor & 2 & 50 \\
Tip122 power transistor & 1 & 50 \\
Push switch and cap & 3 & 20 \\
Power switch & 1 & 10 \\
12v relay & 2 & 20 \\
Bd547 transistor & 2 & 10 \\
Project structure board & 1 & 500 \\
Temperature sensor & & 10 \\
Total Cost & & 6900 TK (BD) \\
\hline
\end{tabular}


Some bag uses are here. For intermittent, positive pressure ventilation, maximum expiratory pressure in preterm newborns, judging necessary pressure before the baby is connected to the follower. There's a slight of a carrier misuse. Do not use the bag for the free flow of oxygen, high pressure can lead to pneumothorax, Long breathing with 100percentage oxygenation can cause adverse health effects for oxygen and bags must be avoided before esophageal evacuation and diaphragm herniation in meconium colored liquid [29]-[35].

\section{RESULTS}

The results and discussion of the calibration of needle valve is represented here. The position of the needle valve was adjusted, and the corresponding digital voltage and flow were recorded. In this work, the curve fitting is performed, and the equation relativity flow and digital voltage is obtained.

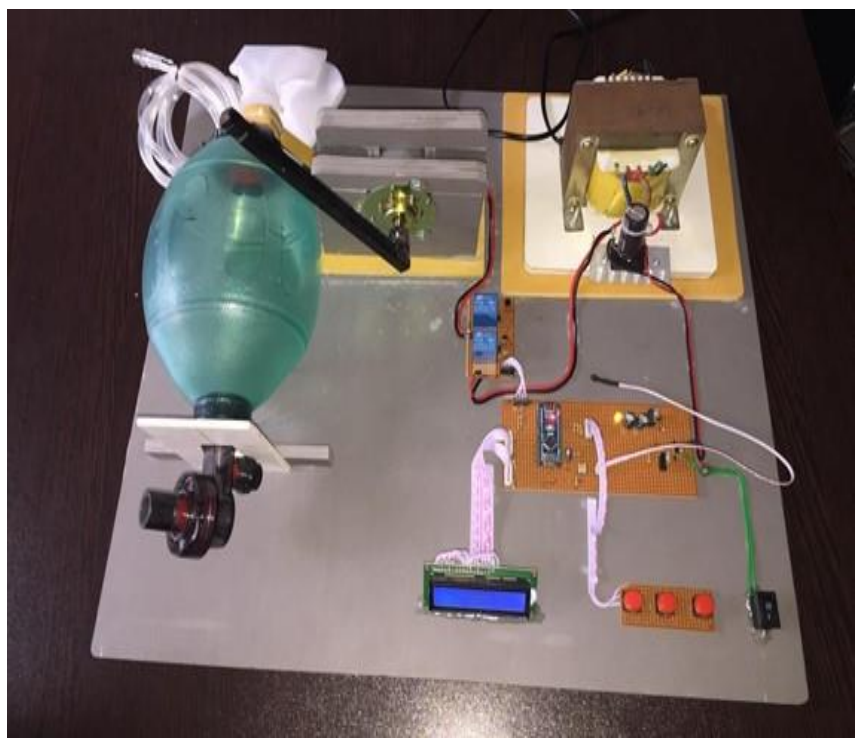

Fig. 6.Hardware part of the prototype.

The advantages of this work are simple-to-control, easy to use, nobody needs a medical specialist to run it, we can use it at home, cheap installation costs, dependable in an emergency.

\section{CONCLUSION}

A prototype device is created in this study to help patients who can respire partly by themselves. This gadget has a basic and dependable design, which the sufferer may readily accept. This study focuses on reducing the components and enhancing device efficiencies, so that they feel as comfortable as the ordinary air conditioner when using this gadget for the patient. In this article needle valve, together with the potential meter, the flow analyzer is replaced to make the whole set-up economical. Because programming is easy, Arduino Uno panel has been utilized. The study led to the invention of the laboratory model fan. The device's operational model has been built. An imitation lung has been appeared. The model mechanism was operated by the breath and tidal volume medical representation, including the regulated arm and batteries alarm. BVMs are widely accessible on the market, which is why their induction also has a favorable burden on subsequent proceedings. Work is also being proposed on several areas with the resultant results, including strategies to limit mortality to their lowest rate, reduction weight and prolonged battery life. A more productive use of alarms will be tested. During the last phase, testing was pushed to meet the requirements set for the ventilator to make the product competitive with the marketplace, for the reason of evaluating the ventilation on a lung model. In future, we will perfectly and safely build our task mode. To check everything with our smart phone, we also add GSM and pulse sensor.

\section{REFERENCES}

[1] L. Acho, Vargas, A. N., \& Pujol-Vázquez, G., "Low-Cost, OpenSource Mechanical Ventilator with Pulmonary Monitoring for COVID19 Patients", In Actuators Multidisciplinary Digital Publishing Institute, vol. 9, Issue. 3, p. 84, 2020. MPDI.

[2] C. Putensen, B. Hentze, S. Muenster, \& T. Muders, "Electrical impedance tomography for cardio-pulmonary monitoring", The Journal of clinical medicine, vol. 8, Issue. 8, p-1176, 2019. NLMNIH.

[3] M. H. Jang, M. J. Shin, \& Y. B. Shin, "Pulmonary and physical rehabilitation in critically ill patients", The Journal of Acute and critical care, vol. 34, Issue. 1, 2019.doi=10.4266/acc.2019.00444.

[4] A. V. Radogna, P. A. Siciliano, S. Sabina, E. Sabato, \& S. Capone, "A low-cost breath analyzer module in domiciliary non-invasive mechanical ventilation for remote COPD patient monitoring", The Journal of Sensors, vol. 20, Issue. 3, p. 653, 2020.

[5] A. L. M. Carpio, \& J. I. Mora, "Ventilator management. Stat Pearls", Internet, 2020

[6] R. Coudroy, L. Chen, T. Pham, T. Piraino, I. Telias, \& L. Brochard, "Acute respiratory distress syndrome: respiratory monitoring and pulmonary physiology", The Seminars in respiratory and critical care medicine, Thieme Medical Publishers, vol. 40, Issue. 01, p. 066 , 2019.Epub 2019 May 6. PMID: 31060089.

[7] T. J. Wang, B. Chau, M. Lui, G. T. Lam, N. Lin, \& S. Humbert, "PMR and pulmonary rehabilitation for COVID-19", American journal of physical medicine \& rehabilitation. 2020.

[8] S. S. Srinivasan, K. B. Ramadi, F. Vicario, D. Gwynne, A. Hayward, D. Lagier, \& G. Traverso, "A rapidly deployable individualized system for augmenting ventilator capacity", The Journal of Science Translational Medicine, vol. 12, p. 549, 2020.

[9] L. C. Myers, M. K. Faridi, P. Currier, \& C. A. Camargo Jr, "ICU utilization for patients with acute exacerbation of chronic obstructive pulmonary disease receiving noninvasive ventilation", Critical care medicine, vol. 47, Issue. 5, p. 677, 2019.

[10] J. Liu, Z. Meng, Y. Zhang, G. Wang, \& J. Xie, "Effect of intraoperative lung-protective mechanical ventilation on pulmonary oxygenation function and postoperative pulmonary complications after laparoscopic radical gastrectomy”, Brazilian Journal of Medical and Biological Research, vol. 52, Issue. 6, 2019. doi:10.1590/1414-431x20198523.

[11] A. P. Gautam, R. Arena, S. Dixit, \& A. B. Silva, "Pulmonary rehabilitation in COVID-19 pandemic era: The need for a revised approach", Respirology (Carlton, Vic.), 2020.

[12] D. Lv, X. Chen, L. Mao, J. Sun, G. Wu, Z. Lin, \& Y. Jiang, "Pulmonary function of patients with 2019 novel corona virus induced pneumonia: a retrospective cohort study", Annals of Palliative Medicine. 2020. doi 10.21037/apm-20-1688.

[13] F. Klimeš, A. Voskrebenzev, M. Gutberlet, A. L. Kern, L. Behrendt, R. Grimm, \& J. V. Claussen, "3D phase-resolved functional lung ventilation MR imaging in healthy volunteers and patients with chronic pulmonary disease",The Journal ofMagnetic Resonance in Medicine vol. 85, Issue. 2, p. 912, 2021. Magnetic Resonance in Medicine.

[14] B. R. Celli, \& J. A. Wedzicha, "Update on clinical aspects of chronic obstructive pulmonary disease", The Journal of New England Journal of Medicine, vol. 381, Issue. 13, p. 1257, 2019.

[15] M. Macrea, S. Oczkowski, B. Rochwerg, R. D. Branson, B. Celli, J. M. Coleman III, \& R. L. Owens, "Long-term noninvasive ventilation in chronic stable hypercapnic chronic obstructive pulmonary disease. an official american thoracic society clinical practice guideline", The Journal of American Journal of Respiratory and Critical Care Medicine, vol. 202, Issue. 4, p. 74, 2020. American Journal of Respiratory and Critical Care Medicine. 
[16] V. Tomicic, \& R. Cornejo, "Lung monitoring with electrical impedance tomography: technical considerations and clinical applications",The Journal of thoracic disease, vol. 11, Issue. 7, p. 3122, 2019. Journal of thoracic disease

[17] J. Wosik, M. Fudim, B. Cameron, Z. F. Gellad, A. Cho, Phinney, D., \&Tcheng, J.,"Telehealth transformation: COVID-19 and the rise of virtual care", TheJournal of the American Medical Informatics Association, vol. 27, Issue. 6, p. 957, 2020. AMIA.

[18] Y. Fang, J. Zhou, X. Ding, G. Ling, \& S. Yu, "Pulmonary fibrosis in critical ill patients recovered from COVID-19 pneumonia: Preliminary experience", The American Journal of Emergency Medicine, vol. 38, Issue. 10, p. 2134, 2020. Medicine.

[19] R. Liu, J. Wang, G. Zhao, \& Z. Su, "Negative pressure pulmonary edema after general anesthesia: A case report and literature review", Medicine, vol. 98, Issue. 17, 2019.

[20] M. A. Al Rakib, "GSM Based Home Safety and Security System", The Journal of the European Journal of Engineering and Technology Research, vol. 6, Issue. 6, p. 69, 2021. European Journal of Engineering and Technology Research.

[21] M. A. Al Rakib, "Design and Simulation-Based Parametric Studies of a Compact Ultra-Wide Band Antenna for Wireless Capsule Endoscopy System at Inside Body Environment", International Journal of Electrical and Electronic Engineering \& Telecommunications-2021. IEEE.

[22] M. A. Al Rakib, "Dry and Wet Waste Segregation and Management System", The Journal of the European Journal of Engineering and Technology Research, vol. 6, Issue. 5, p. 129, 2021. European Journal of Engineering and Technology Research.

[23] S. Uddin, M. M. Rahman, "Pure Sine Wave Inverter Design for Street Light Emergency Backup System", International Journal for Innovative Research in Science \& Technology, vol. 7, issue 10, 2021.

[24] M. A. Al Rakib, "Implementation of Inverse Define Minimum Time Under and Over Voltage Relay", International Journal of Smart Gridij Smart Grid, vol.5.2, p. 88-93, 2021.Journal of Smart Grid.

[25] M. A. Al Rakib, "Energy Harvesting Technology from Human Motion",2020 2nd International Conference on Advanced Information and Communication Technology (ICAICT), 2020. IEEE.

[26] M. S. Mahamud, "Mouchak-An IoT Basted Smart Beekeeping System Using MQTT",2019 4th International Conference on Robotics and Automation Engineering (ICRAE), 2019.IEEE.

[27] M. Islam, G. M. Bhuiyan, F. I. Abbas, "Effects of interionic pair interactions on atomic transport properties of liquid Al", Indian Journal of Physics, p. 1, 2021. Springer.

[28] F. I. Abbas, "Critical Properties of Segregation for $\mathrm{Al}_{1-\mathrm{x}} \mathrm{Bi}_{\mathrm{x}}$ Liquid Binary Alloys", Journal of the Physical Society of Japan, vol. 89, Issue. 11, p. 114004, 2020. The Physical Society of Japan.

[29] N. E Dubinin, G. M. Bhuiyan, F. I. Abbas, "Effective Wills-Harrison Pair Interaction in Liquid Au", Russian Metallurgy (Metally), vol. 2019, Issue 8, p. 835, 2019. Springer.

[30] G. M. Bhuiyan, F. I. Abbas, "Local minimum in pair potentials of polyvalent metals: A limitation of pseudopotential theory", International Journal of Modern Physics B, vol. 33, Issue. 7, 2019. World Scientific Publishing Company: Wiley.

[31] F. I. Abbas, G. M. Bhuiyan, "Thermodynamic and transport properties of aluminium (Al)-based liquid binary alloys: Research work for Sustaining developing alloys for energy sector", Department of Theoretical Physics, 2019. Dhaka University Institutional Repository, University of Dhaka. 2019

[32] F. I. Abbas, G. M. Bhuiyan, "A study of thermodynamics of mixing for $\mathrm{Al}_{1-} \mathrm{Sn}_{\mathrm{x}}$ liquid binary alloy", Journal of non-crystalline solids, vol. 481, p. 391, 2018. Elsevier.

[33] F. I. Abbas, G. M. Bhuiyan, A. Z. Ziaudin, "Energy of mixing and entropy of mixing for $\mathrm{Cu}_{\mathrm{x}} \mathrm{Al}_{1-\mathrm{x}}$ liquid binary alloys", Cornell University Library, arXiv preprint arXiv:1607.05827, 2016.

[34] M. A. Al Rakib, "IoT based Controlling of Power Grid", The Journal of the European Journal of Engineering and Technology Research, vol. 6, Issue. 6, p. 54, 2021.European Journal of Engineering and Technology Research.

[35] S. Ahmad, "Design of a Compact Simple Structured Dual-band Patch Antenna for Wireless On-body Medical and Sports Devices", 2021 2nd International Conference on Robotics, Electrical and Signal Processing Techniques (ICREST), p.577, 2021. IEEE.

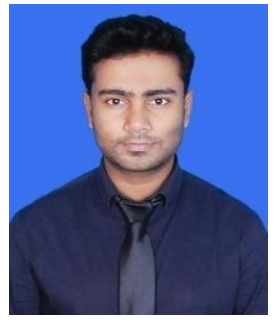

Md Abdullah Al Rakib received Bachelor of Science (B.Sc.) in EEE from American International University-Bangladesh (AIUB). He started his career in September 2018 at City University-Bangladesh (CUB) as Lecturer in the Dept. of EEE. His research interest is focused on Power, Electronics, IoT, and Telecommunication.

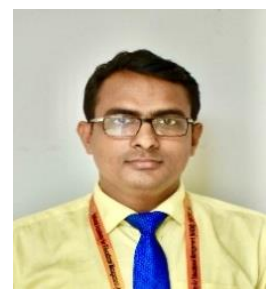

Md. Moklesur Rahman received his M.Sc. in Physics from Dhaka University, Bangladesh in 2012 and B.Sc. in Physics from Dhaka University, Bangladesh in 2011. He joined as the BCS Education cadre in 2016. He is currently working as a Lecturer in the Department of Physics, Shahzadpur Govt. College, Sirajganj, Bangladesh. He has more than 08 years of experience in teaching and research. His research interests are in Material science, IoT and Condensed Matter Physics.

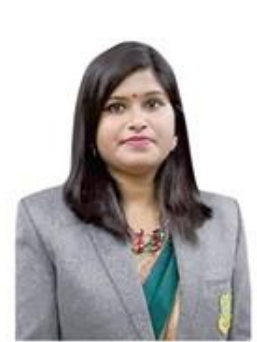

Mousume Samad received her B.Sc. Engineering from Rajshahi University of Engineering \& Technology (RUET) in 2014. She is pursuing her M.Sc in Engineering degree from the Department of Electronics and Communication Engineering (ECE) of Khulna University of Engineering \& Technology (KUET). At present, she is working as a Senior Lecturer in the department of Information and Communication Engineering (ICE) of Bangladesh Army University of Engineering and Technology (BAUET), Bangladesh. Her research interests include Antenna Engineering, RF communication engineering, Image processing, and Optical Fiber Communication etc.

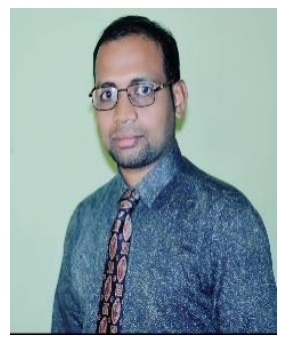

Sanjib Islam received his Bachelor of Science (B.Sc.) in EEE from Independent University, Bangladesh (IUB). He started his career as a researcher in the Dept. of EEE at IUB. His research interest is focused on Material science and Telecommunication Engineering.

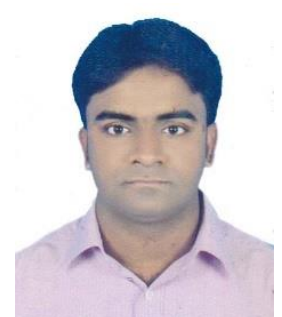

Md. Ashiqur Rahman has completed his undergraduation degree (B.Sc.) \& graduation degree (M.Sc.) in Physics from Department of Physics, University of Dhaka. He is currently doing his $\mathrm{Ph} . \mathrm{D}$. research at Graduate School of Science, Tokyo Metropolitan University at Tokyo prefecture Japan.He served as a Lecturer in the Department of Physics, Comilla University (CoU), Bangladesh from $31^{\text {th }}$ July, 2016 to $30^{\text {th }}$ November, 2018. He promoted as an Assistant Professor in the same University from $1^{\text {st }}$ December 2018. Still Now, he has worked as an Assistant Professor in the Department of Physics, Comilla University (CoU), Bangladesh. His research interests are inorganic nanotube, carbon nanotube, thermoelectric materials, Superconductivity, Nanotechnology and Optics.

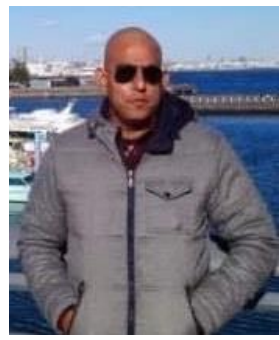

Dr. Fysol Ibna Abbas received his Ph.D. in Material Science from the Department of Theoretical Physics, University of Dhaka, Bangladesh. The worldwide well-known Professor Dr. Arghya Taraphder, (IIT-Indian Institute of Technology Kharagpur, India) \& Professor Dr. David J. Gonzalez (The University of Valladolid, Valladolid province, Spain) were the doctoral thesis reviewer of him from 22 July 2018 to 25 February 2019. Both of them are specialists in Material Science research works. Dr. Abbas completed his M.Sc from the Department of Theoretical Physics (Condensed Matter Research Group) at the University of Dhaka in 2012. From the same university, he completed his B.Sc in Physics (2010). In the 
Graduate school of science, Tokyo Metropolitan University at Tokyo prefecture, Japan, Dr. Abbas is currently working as an active researcher. In his service career, he served as an Assistant Professor in the Department of Electrical \& Electronic Engineering, City University Bangladesh (CUB) from 2018 to 2021 . He has also served as a faculty member in the MNS Department at BRAC University from 2013 to 2018. Dr. Abbas has more than 11 years of experience in teaching and research. His research interests are Liquid binary alloys, High entropy alloys (HEA), Thermoelectric materials (TE), Functional materials application, Superconductivity (SC), Photonics, Nanotechnology, Optics, and Solar cell. 